\title{
Barriers and Facilitators to Compliance with a State Healthy Eating Policy in Early Care and Education Centers
}

\author{
Daniel A. Zaltz, MPH,' Russell R. Pate, PhD, Jennifer R. O'Neill, PhD, MPH, \\ Brian Neelon, $\mathrm{PhD}$, and Sara E. Benjamin-Neelon, PhD, JD, RD 1,3
}

\section{Abstract}

Background: Early care and education (ECE) policies can improve childhood obesity risk factors. We evaluated barriers and facilitators to implementing mandatory nutrition standards for foods provided in South Carolina ECE centers serving lowincome children, comparing centers participating in the Child and Adult Care Food Program (CACFP) with non-CACFP centers.

Methods: We mailed 261 surveys (demographics, policies and practices, barriers and facilitators) to center directors after new state nutrition standards were implemented in South Carolina. We conducted univariate and bivariate analyses to explore relationships between barriers, facilitators, and center-level characteristics, by CACFP status.

Results: We received 163 surveys (62\% response rate). Centers had a median [interquartile range (IQR)] of 5 (4-7) classrooms and 59 (37.5-89) total children enrolled. More than half (60.1\%) of directors reported they were moderately or fully informed about the standards. The most common barriers were food costs $(17.8 \%)$ and children's food preferences $(17.8 \%)$. More non-CACFP directors reported food costs as a barrier $(28.6 \%$ vs. $6.5 \%, p<0.001)$, having to spend additional money on healthier foods $(48.8 \%$ vs. $28.6 \%$, $p=0.01)$, and having to provide additional nutrition education to parents $(28.6 \%$ vs. $11.7 \%, p=0.01)$, compared with CACFP directors.

Conclusions: Center directors were generally well informed about the nutrition standards. The most common barriers to implementing the standards were food costs and children's food preferences. Centers participating in CACFP may be in a better position to adhere to new state nutrition standards, as they receive some federal reimbursement for serving healthy foods and may be more accustomed to regulation.

Keywords: child care; healthy eating; obesity; policy; regulations

\section{Introduction}

$\mathbf{H}$ ealthy eating is an important component of obesity prevention in early childhood. ${ }^{1-3}$ Nearly onequarter (22.8\%) of American children ages 2 through 5 years are overweight, ${ }^{4}$ and thus at an increased risk of becoming obese in adulthood. ${ }^{5-7}$ Dietary habits, which develop early in life and often track into adulthood, ${ }^{1,8}$ can significantly impact the lifetime risk of obesity., 3

Recent interventions to improve diet quality have targeted early care and education (ECE) settings, ${ }^{10-15}$ where more than $60 \%$ of children younger than 5 years spend up to $33 \mathrm{~h} /$ week or more ${ }^{16}$ and may consume one-half to two-thirds of their daily calories. ${ }^{17,18}$ Policy interventions have the potential to improve healthy eating in ECE settings, ${ }^{15,19}$ and may be more sustainable than programs focused on individual behavior change. ${ }^{15,19-21}$ The Centers for Disease Control and Prevention (CDC), National Academy of Medicine, Department of Health and Human Services (HHS), and United States Department of Agriculture (USDA) have all published healthy eating policy recommendations for ECE settings. ${ }^{2,9,22,23}$ These recommendations include limits (e.g.,

\footnotetext{
'Department of Health, Behavior, and Society, Johns Hopkins Bloomberg School of Public Health, Baltimore, MD.

${ }^{2}$ Department of Exercise Science, Arnold School of Public Health, University of South Carolina, Columbia, SC.

${ }^{3}$ Department of Public Health Sciences, Medical University of South Carolina, Charleston, SC.
} 
no sugar-sweetened beverages may be served) or minimum amounts (e.g., fruits and vegetables daily) of certain types of food that are provided to or served by ECE centers. Despite these resources, state and local governments still have room to improve their healthy eating policies for ECE. ${ }^{15}$

State governments are largely responsible for regulating ECE. ${ }^{3,15,24,25}$ States are varied, however, in the type and quality of their healthy eating policies. ${ }^{3}$ In addition, some policies are implemented as part of federal ECE subsidy programs. For example, the Child and Adult Care Food Program (CACFP), ${ }^{26}$ a broad, federally funded program, provides financial support for foods and beverages served to low-income children in participating ECE centers. The federal government sets income-based eligibility criteria for CACFP participation, and participating centers are required to meet mandatory nutrition rules. ${ }^{26}$ There is some evidence to suggest that centers participating in CACFP serve more fruits, ${ }^{27}$ vegetables, ${ }^{27,28}$ and whole grains, ${ }^{14,29}$ and fewer sugar-sweetened beverage ${ }^{27}$ and high-fat meats. ${ }^{14,27}$

Prior research has established several perceived barriers to implementing healthy eating policies in ECE, including food costs, additional time needed to provide healthier foods, limited storage or facilities, and children's food preferences. ${ }^{30-36}$ Researchers who evaluated healthy eating policies implemented in New York City, ${ }^{11}$ Delaware, ${ }^{14}$ and South Carolina ${ }^{10}$ have reported varying levels of compli-

\section{Table I. ABC Grow Healthy Standards}

\begin{tabular}{l} 
Beverages \\
\hline Skim or I\% milk for children 2 years and older \\
\hline Sugar-sweetened beverages not served \\
\hline Juice allowed only once per day or less in four-ounce servings \\
\hline Fruits and vegetables \\
\hline At least two different fruits served two or more times per day \\
\hline Vegetable other than white potatoes served at least one time \\
per day \\
\hline Fried or prefried vegetables served one time per week or less \\
\hline Whole grains \\
\hline Whole-grain foods served once per day \\
\hline Other foods
\end{tabular}

High-fat meats served two times per week or less

Sweet food items served two times per week or less

Policies and practices

Staff attend nutrition training at least one time per year

Children learn about nutrition at least one time per week

Do not use food as a reward or punishment

Create and consistently implement a written nutrition policy ance. Overall, there is a dearth of research on the barriers, facilitators, and implementation of these policies in ECE.

We previously evaluated center-level compliance with new healthy eating standards in South Carolina ECE and found modest improvements. ${ }^{10}$ The standards, called ABC Grow Healthy, include limits on certain types of foods and beverages, as well as minimum amounts and frequencies of healthy foods served at the center (Table 1). The ABC Grow Healthy standards are implemented through the ABC Program, which provides subsidies for child care to families making less than $150 \%$ of the federal poverty level. The ABC Program includes a quality rating and improvement system (QRIS) that rates participating ECE centers based on their care standards. Participating center directors choose different levels of the QRIS, each with corresponding standards of care. ${ }^{37}$

The purpose of this study was to evaluate barriers and facilitators to implementing the ABC Grow Healthy nutrition standards. A secondary goal was to compare barriers and facilitators by CACFP participation status. We hypothesized that CACFP centers would be more amenable to changes to the new ABC Grow Healthy standards, as they may be more accustomed to adhering to external regulations and may already be serving higher quality foods.

\section{Methods}

\section{Overview}

For this cross-sectional analysis, we used data collected from a survey of ECE center directors who participate in the South Carolina ABC Program, and thus were subject to the $\mathrm{ABC}$ Grow Healthy standards. The standards were implemented in 2012 and centers were expected to comply by October 2012. We mailed 261 surveys in early 2013 and received 163 responses (62\% response rate). The Institutional Review Boards of Duke University Medical Center and the University of South Carolina approved this study.

\section{Survey}

Researchers created the survey based on Whitaker et al. Study of Healthy Activity and Eating Practices and Environments in Head Start (SHAPES), ${ }^{38}$ and Helfrich et al. ${ }^{39}$ Organizational Readiness to Change Assessment, an instrument of the Promoting Action on Research in Health Services framework. ${ }^{40,41}$ The framework is applicable to evaluating policy implementation at the local level, ${ }^{41}$ because it focuses on the role of local facilitators-in this case, center directors-during the implementation of health policies. ${ }^{42}$

\section{Demographics}

We collected center-level data on the age, race, ethnicity, and total number of children enrolled, as well as the number of classrooms and paid staff at each center. We also collected data on the age, education, and total years of experience of each director, and the participation status of each center in the CACFP. 


\section{Policies and Practices}

We collected data on the present healthy eating policies and practices at each center. The questions related to policies and practices, which corresponded to the new ABC Grow Healthy standards, were partially derived from Benjamin et al. ${ }^{43}$ and Whitaker et al. ${ }^{38}$ These included practices related to mealtime behavior, use of food as reward or punishment, and nutrition education for children and providers.

\section{Barriers}

Center directors indicated from a list of inclusive options their perceived barriers to implementing the healthy eating standards, and what changes they made, if any, to comply with the standards. The list of potential barriers was derived from previous research on directors' experiences with nutrition policies and practices in ECE. ${ }^{38,44}$ The list included barriers associated with resources (e.g., food cost, appropriate kitchen space), parental support of new standards, and child reactions to new foods.

\section{Facilitators}

We examined facilitators by asking center directors about their involvement with and knowledge of the new standards, using elements from both Whitaker et al. ${ }^{38}$ and Helfrich et al..$^{39}$ Directors responded to six questions about their perceptions of being informed of the new standards. We grouped these responses into three categories: moderate extent/very much, somewhat, and not at all/small extent. Directors rated their agreement with five declarative statements about perceptions of being involved with the implementation of the standards. We dichotomized these responses into agree/strongly agree and disagree/ strongly disagree.

\section{Table 2. Demographic Characteristics of Child Care Centers in South Carolina,} by Child and Adult Care Food Program Participation ( $n=163)$

\begin{tabular}{|c|c|c|c|}
\hline & All $(n=163)$ & CACFP $(n=77)$ & Non-CACFP $(n=84)$ \\
\hline Center characteristics & \multicolumn{3}{|c|}{ Median (IQR) } \\
\hline Children enrolled & $59(37.5-89)$ & $61(40-86)$ & $57(34.5-88)$ \\
\hline Subsidized children enrolled & $8(3-18)$ & $12(4.5-32.5)$ & $6(2-12)$ \\
\hline \multicolumn{4}{|l|}{ Child race $(\%)$} \\
\hline White & $53.5(|7.2-8| .2)$ & $30(9.5-67)$ & 80 (29.7-91.5) \\
\hline Black/African American & $41(10.4-85)$ & $62(30-95)$ & $20(5-70)$ \\
\hline Multiple/more than one race & $3(1-7.2)$ & $5(2-10)$ & $2(1-5)$ \\
\hline Latino/Latina/Hispanic ethnicity & $2(1-5)$ & $2(1-6.8)$ & $1.7(0-4.7)$ \\
\hline Paid staff & $10(6-15)$ & $10(6-15)$ & $9(6-15)$ \\
\hline Classrooms & $5(4-7)$ & $5(4-6)$ & $5(4-7)$ \\
\hline \multicolumn{4}{|l|}{ Director characteristics } \\
\hline Age & $52(42-59)$ & $52.5(45-59.2)$ & $48(4 I .8-57)$ \\
\hline Years employed & $20(12-27.4)$ & $20(12.4-28.1)$ & $20(10.5-25)$ \\
\hline Education & \multicolumn{3}{|c|}{$\%(n)$} \\
\hline High school or technical college & $19.1(30)$ & $17.6(13)$ & $21(17)$ \\
\hline Some/all associate degree & $26.1(4 I)$ & $27(20)$ & $25.9(21)$ \\
\hline Some/all college or university & $26 . I(4 I)$ & $29.7(22)$ & $21(17)$ \\
\hline Some/all graduate school & $28.7(45)$ & $25.7(19)$ & $32.1(26)$ \\
\hline Gender, female & $97.5(154)$ & $97.3(73)$ & $97.5(79)$ \\
\hline \multicolumn{4}{|l|}{ Director race (\%) } \\
\hline White & $60.1(98)$ & $50.6(39)$ & $69(58)$ \\
\hline Black/African American & $35.6(58)$ & $46.8(36)$ & $25(2 I)$ \\
\hline Multiple/more than one race & $4.3(7)$ & $2.6(2)$ & $6(5)$ \\
\hline Latino/Latina/Hispanic ethnicity & $2.7(4)$ & $2.9(2)$ & $2.6(2)$ \\
\hline
\end{tabular}

CACFP, Child and Adult Care Food Program; IQR, interquartile range. 


\section{Analysis}

We calculated medians and IQRs for continuous demographic variables because the data were not normally distributed, and frequencies for categorical variables. We compared results between centers that did and did not participate in CACFP. We conducted Wilcoxon rank-sum tests for continuous variables and exact Pearson chi-squared tests or Fisher's exact tests for categorical variables to examine differences by CACFP status. We performed all analyses using $\mathrm{R}$ software 3.4.2 (R Foundation for Statistical Computing, Vienna, Austria) with a significance level of $p<0.05$.

\section{Results}

\section{Demographics}

Seventy-seven centers participated in CACFP, 84 did not, and two did not provide their participation status. Centers had a median (IQR) of 59 (37.5-89) total children enrolled, 10 (6-15) paid staff, and 5 (4-7) classrooms. Enrolled children were $53.5 \%$ white and $41 \%$ black/African American. Directors were a median (IQR) of 52 (42-59) years old with 20 (12-27.4) years of experience in ECE. Nearly all $(97.5 \%)$ were female and $28.7 \%$ had completed at least some graduate education. Directors were $60.1 \%$ white and $35.6 \%$ black/African American (Table 2).

\section{Policies and Practices}

Most $(90 \%)$ centers had a written nutrition policy. Almost half of the centers $(46.6 \%)$ reported that they provide children with nutrition education more than once per year, and nearly all stated that they serve fruit other than juice daily $(95.1 \%)$ and have at least one staff member join children at the table for meals and snacks (94.2\%). Compared with non-CACFP centers, more centers participating in CACFP reported having a written nutrition policy $(95.8 \%$ vs. $83.3 \%, p=0.03)$, requiring staff to attend nutrition trainings more than once per year ( $46.6 \%$ vs. $20.9 \%$, $p=0.001$ ), and serving healthy foods or nonfood treats to celebrate holidays or events $(80.3 \%$ vs. $59.4 \%, p=0.01)$. Fewer centers participating in CACFP reported serving children juice drinks containing less than $100 \%$ fruit juice, compared with non-CACFP centers $(2.7 \%$ vs. $23.5 \%$, $p=0.0006$ ) (Table 3).

\section{Barriers}

Overall, directors reported cost (17.8\%) and children not liking healthier foods $(17.8 \%)$ as the most prevalent barriers to implementing the standards (Table 4). Among all directors, $12.9 \%$ reported experiencing no challenges implementing the standards. Compared with non-CACFP directors, fewer CACFP directors reported cost as a barrier (6.5\% vs. $28.6 \%, p=0.0004)$. Directors (CACFP and nonCACFP combined) were most likely to report spending more money $(39.3 \%)$ and providing nutrition education to parents $(20.2 \%)$ as necessary changes to comply with the standards. Few $(3.7 \%)$ reported no changes made to comply with the standards. Fewer CACFP directors reported needing to spend additional money $(28.6 \%$ vs. $48.8 \%, p=0.014$ ) or provide nutrition education to parents $(11.7 \%$ vs. $28.6 \%, p=0.014)$ as necessary changes to comply with the standards, compared with non-CACFP directors.

\section{Facilitators}

More than half of the directors (60.1\%) reported they were informed ("moderate extent" or "very much") of the standards (Table 5). Directors were most likely to report being informed of the daily implications of the nutrition standards $(62.6 \%)$, and least likely to report receiving

\begin{tabular}{|c|c|c|c|c|}
\hline \multirow[b]{2}{*}{ Center policy } & $\begin{array}{c}\text { All } \\
(n=163)\end{array}$ & $\begin{array}{l}\text { CACFP } \\
(n=77)\end{array}$ & $\begin{array}{c}\text { Non-CACFP } \\
(n=84)\end{array}$ & \multirow[b]{2}{*}{$\mathbf{p}$} \\
\hline & \multicolumn{3}{|c|}{$\%(n)$} & \\
\hline Written nutrition policy for center & $90(126)$ & $95.8(69)$ & $83.3(55)$ & 0.03 \\
\hline Staff attend nutrition trainings more than one time per year & $34.5(49)$ & $46.6(34)$ & $20.9(14)$ & 0.001 \\
\hline Serve fruit other than juice daily & $95.1(136)$ & $95.9(70)$ & $94.1(64)$ & 0.92 \\
\hline At least one staff joins children at table for meals/snacks & $94.2(131)$ & $97.2(69)$ & $90.9(60)$ & 0.23 \\
\hline Healthy foods or nonfood treats used to celebrate holidays or special events & $70.4(100)$ & $80.3(57)$ & $59.4(4 I)$ & 0.01 \\
\hline Children may be served juice drinks $<100 \%$ fruit juice & $12.6(18)$ & $2.7(2)$ & $23.5(16)$ & 0.0006 \\
\hline Children may be served flavored milk & $34.7(50)$ & $37.8(28)$ & $30.9(21)$ & 0.49 \\
\hline Staff may consume their own foods/beverages in front of children & $27.5(39)$ & $19.4(14)$ & $35.3(24)$ & 0.06 \\
\hline Children provided nutrition education more than once per year & $46.6(62)$ & $49.2(32)$ & $42.4(28)$ & 0.43 \\
\hline
\end{tabular}




\begin{tabular}{|c|c|c|c|c|}
\hline \multirow[b]{2}{*}{ Barrier } & All $(n=163)$ & CACFP $(n=77)$ & Non-CACFP $(n=84)$ & \multirow[b]{2}{*}{$p$} \\
\hline & \multicolumn{3}{|c|}{$\%(n)^{a}$} & \\
\hline Not enough money & $17.8(29)$ & $6.5(5)$ & $28.6(24)$ & 0.0004 \\
\hline Children do not like healthier foods & $17.8(29)$ & $15.6(12)$ & $20.2(17)$ & 0.57 \\
\hline No challenges & $12.9(21)$ & $15.6(12)$ & $9.5(8)$ & 0.35 \\
\hline Parents do not support the idea of healthier foods & $9.8(16)$ & $6.5(5)$ & $13.1(1 \mathrm{I})$ & 0.19 \\
\hline Lack of control over food from distributor & $6.7(\mathrm{II})$ & $6.5(5)$ & $7.1(6)$ & 1.0 \\
\hline Lack of kitchen or space for food preparation & $4.9(8)$ & $3.9(3)$ & $6(5)$ & 0.72 \\
\hline Staff lack knowledge to prepare healthier foods & $4.9(8)$ & $3.9(3)$ & $6(5)$ & 0.72 \\
\hline \multicolumn{5}{|l|}{ Changes made to comply with standards } \\
\hline Spent more money & $39.3(64)$ & $28.6(22)$ & $48.8(4 I)$ & 0.01 \\
\hline Provided nutrition education to parents & $20.2(33)$ & $11.7(9)$ & $28.6(24)$ & 0.01 \\
\hline Provided nutrition training for staff & $17.2(28)$ & $14.3(11)$ & $19(16)$ & 0.55 \\
\hline Purchased additional equipment for food preparation & $6.7(11)$ & $5.2(4)$ & $8.3(7)$ & 0.54 \\
\hline No changes necessary & $3.7(6)$ & $6.5(5)$ & $1.2(1)$ & 0.10 \\
\hline
\end{tabular}

${ }^{a}$ Frequencies and $n$ values refer to the total number of directors who selected each respective barrier or change. Directors were prompted to select as many or few options from this list as applied.

direct communication about the standards $(27.8 \%)$. Most $(80.7 \%)$ directors agreed that they could ask questions about the nutrition standards, and about half (51.1\%) agreed that they could provide input into the decisions made at their center related to the standards.

\section{Discussion}

We evaluated barriers and facilitators to implementing the South Carolina ABC Grow Healthy standards from the perspective of center directors. The majority of directors reported they were both informed and had enough information to comply with the new standards. The most common barriers to implementing the new standards were cost and the perception that children would not like healthier foods.

Cost is often a perceived barrier to improving nutrition in ECE. ${ }^{33,34}$ It is important for researchers and policymakers to address the economic impacts of nutrition policies in $\mathrm{ECE},{ }^{35}$ given that requiring healthier foods has been shown to increase overall costs. ${ }^{35,45}$ New CACFP rules, which took effect from October 1, 2017, made substantial changes to the nutrition standards for foods served in ECE, including a greater variety of approved fruits and vegetables, more whole grains, and reductions to added sugars and saturated fats. ${ }^{46}$ Future research should explore if these changes to approved foods impact the overall cost of providing healthy foods in ECE.

Another barrier to implementing the ABC Grow Healthy Standards was children's food preferences. Young children are often hesitant to try new foods, ${ }^{33,47,48}$ and may be biologically inclined to prefer sweet, salty, and high-fat foods. ${ }^{48-50}$ Policies such as the ABC Grow Healthy standards can improve dietary habits of young children by influencing their food preferences through repeated exposure. ${ }^{51-53}$ In addition, parents and ECE providers can influence children's eating preferences, which may carry over to adulthood. ${ }^{47,48,54-56}$ For example, children may be more inclined to eat new and healthy foods if they are involved in the preparation of those foods, ${ }^{57}$ and children may be more likely to consume vegetables in ECE if they engage in a garden-based education program. ${ }^{58}$ There is, however, a need to study the impact of healthy eating standards on food waste, ${ }^{59}$ especially when cost is a common barrier to improving nutrition in ECE.

We also found that CACFP and non-CACFP center directors had a favorable perception of being informed of the ABC Grow Healthy program, but many expressed a lack of involvement with its implementation. The ABC Grow Healthy standards were piloted in some centers, and the feedback from this pilot helped inform the design of the final policy. Unlike center-level policies, which are primarily designed and implemented by directors, ${ }^{60}$ broad programs such as ABC Grow Healthy involve many stakeholders outside the center. Further research should look at how center directors, who are critical to the facilitation of new standards and regulations, ${ }^{60-62}$ can continue to be involved in the policymaking processes at the state and federal levels. 
Table 5. Facilitators to Implementing the ABC Grow Healthy Standards,

by Child and Adult Care Food Program Participation $(n=163)$

\begin{tabular}{|c|c|c|c|c|}
\hline \multirow{3}{*}{ How much were you informed overall? } & $\begin{array}{c}\text { All } \\
(n=163)\end{array}$ & $\begin{array}{l}\text { CACFP } \\
(n=77)\end{array}$ & $\begin{array}{c}\text { Non-CACFP } \\
(n=84)\end{array}$ & \multirow{3}{*}{$\begin{array}{c}p \\
0.06\end{array}$} \\
\hline & \multicolumn{3}{|c|}{$\%(n)$} & \\
\hline & & & & \\
\hline Not at all/small extent & $14.5(20)$ & $10.4(7)$ & $18.8(13)$ & \\
\hline Somewhat & $25.4(35)$ & $22.4(15)$ & $29(20)$ & \\
\hline Moderate extent/very much & $60.1(83)$ & $67.2(45)$ & $52.2(36)$ & \\
\hline How much were you informed about the start date? & & & & 0.27 \\
\hline Not at all/small extent & $18.2(25)$ & $15.2(10)$ & $21.7(15)$ & \\
\hline Somewhat & $20.4(28)$ & $19.7(13)$ & $21.7(15)$ & \\
\hline Moderate extent/very much & $61.3(84)$ & $65.2(43)$ & $56.5(39)$ & \\
\hline How much were you informed about implications on your daily routine? & & & & 0.20 \\
\hline Not at all/small extent & $19.6(27)$ & 13.6 (9) & $25.7(18)$ & \\
\hline Somewhat & I8.I (25) & $19.7(13)$ & $15.7(1 \mathrm{I})$ & \\
\hline Moderate extent/very much & $62.3(86)$ & $66.7(44)$ & $58.6(4 I)$ & \\
\hline How much were you informed about implications on job responsibilities? & & & & 0.36 \\
\hline Not at all/small extent & $22.1(30)$ & $21.2(14)$ & $23.5(16)$ & \\
\hline Somewhat & $17.6(24)$ & $13.6(9)$ & $20.6(14)$ & \\
\hline Moderate extent/very much & $60.3(82)$ & $65.2(43)$ & $55.9(38)$ & \\
\hline How much information was communicated to you directly? & & & & 0.16 \\
\hline Not at all/small extent & $27.8(40)$ & $21.4(15)$ & $34.7(25)$ & \\
\hline Somewhat & I8.I (26) & $20(14)$ & $15.3(1 \mathrm{I})$ & \\
\hline Moderate extent/very much & $54.2(78)$ & $58.6(4 I)$ & $50(36)$ & \\
\hline Did you have enough information to comply? & & & & 0.30 \\
\hline Not at all/small extent & $21.7(31)$ & $18.3(13)$ & $25.7(18)$ & \\
\hline Somewhat & $20.3(29)$ & $19.7(14)$ & $20(14)$ & \\
\hline Moderate extent/very much & $58(83)$ & $62(44)$ & $54.3(38)$ & \\
\hline I was able to ask questions about the standards & & & & 0.04 \\
\hline Disagree/strongly disagree & $19.3(28)$ & $12.7(9)$ & $26.4(19)$ & \\
\hline Agree/strongly agree & $80.7(117)$ & $87.3(62)$ & $73.6(53)$ & \\
\hline I was able to give input to the $A B C$ program & & & & 0.73 \\
\hline Disagree/strongly disagree & $58.5(83)$ & $57.1(40)$ & $60(42)$ & \\
\hline Agree/strongly agree & $4 I .5(59)$ & $42.9(30)$ & $40(28)$ & \\
\hline I was able to participate in decision-making on implementing standards & & & & 0.70 \\
\hline Disagree/strongly disagree & $60.4(81)$ & $58.2(39)$ & $61.5(40)$ & \\
\hline Agree/strongly agree & $39.6(53)$ & $41.8(28)$ & $38.5(25)$ & \\
\hline I had control over changes made at my center & & & & 0.54 \\
\hline Disagree/strongly disagree & $50.4(67)$ & $52.3(24)$ & $47(3 \mathrm{I})$ & \\
\hline Agree/strongly agree & $49.6(66)$ & $47.7(31)$ & $53(35)$ & \\
\hline I could have had input into decisions my center made related to standards & & & & 0.26 \\
\hline Disagree/strongly disagree & $48.9(64)$ & $53.1(34)$ & $43.1(28)$ & \\
\hline Agree/strongly agree & $5 I .1(67)$ & $46.9(30)$ & $56.9(37)$ & \\
\hline
\end{tabular}


More directors from non-CACFP centers (compared with CACFP directors) reported concerns over the cost of healthier foods, and reported needing to spend additional money and provide nutrition education to parents to comply with the new standards. We also found several differences between CACFP and non-CACFP center-level nutrition practices. Compared with non-CACFP directors, more CACFP directors reported that their staff received nutrition training, and that their centers had written nutrition policies. More directors from CACFP centers report serving healthy or nonfood items to celebrate special events, and that they prohibit juice drinks less than 100\% fruit juice. There may be a link between CACFP participation and improved nutrition environments in ECE. In other studies, CACFP participation was associated with increased consumption of fruits and vegetables, ${ }^{27,28}$ decreased consumption of sugar-sweetened beverages, ${ }^{27}$ and a greater likelihood of centers offering whole grains and having staff eat the same foods as children. ${ }^{29}$ Unlike our results, however, Liu et al. ${ }^{29}$ found no association between CACFP participation and the existence of written nutrition policies when examining a sample of Midwestern child care centers. Our findings suggest that CACFP centers in South Carolina are more amenable to state-level changes in healthy eating standards. One possible reason for this is that CACFP centers adhere to national standards that can foster a culture of monitoring children's nutrition habits. ${ }^{28}$ The potential positive impacts of CACFP participation may be instructive to policymakers, who can use CACFP standards to design new state regulations.

This study has some limitations. Although we report the relationship between CACFP participation and certain barriers and facilitators, we cannot determine causality with these cross-sectional data. The self-reported data may be subject to social desirability bias, as has been previously reported in a multistate study of nutrition and physical activity practices in ECE. ${ }^{63}$ We did not compare results from this study with the center-level compliance with the ABC Grow Healthy standards, as those findings were reported in a previous study. ${ }^{10}$ In addition, we surveyed center directors and not teachers. Directors from CACFP centers may be more accustomed to regulations and monitoring and thus more likely to report center-level compliance with new regulations. Broadly, directors may be more empowered to make decisions about the overall practices at the center, but teachers are the ones implementing these practices in the classroom. In a recent study, researchers found significant differences between teachers' and directors' perceived barriers to increasing healthy eating in Head Start centers in Texas. ${ }^{36}$ Still, these findings may help improve the successful implementation of future regulations in South Carolina and beyond.

\section{Conclusions}

Researchers and policymakers may wish to collaborate to develop strategies to overcome the perceived cost bar- rier to implementing new healthy eating standards. There is little research on the implementation of new healthy eating policies in ECE ${ }^{64,65}$ and this study helps inform future prospective evaluations. Even less known is how participation in federal food assistance programs such as CACFP may influence the implementation of new policies. ${ }^{29}$ However, there is some evidence that meals served in CACFP centers are already more likely to contain whole-grain foods, fruits and vegetables, and less sugarsweetened beverages. ${ }^{27,29}$ Centers participating in CACFP may be in a better position to adhere to a state nutrition policy, as they receive some federal reimbursement for serving healthy foods and may be more accustomed to regulation.

\section{Acknowledgments}

This study was supported, in part, by a grant from the Robert Wood Johnson Foundation (RWJF), Healthy Eating Research \#69551. The content is solely the responsibility of the authors and does not necessarily represent the official views of the RWJF. The funders had no role in the design of the study, data collection and analysis, decision to publish, or preparation of the article.

\section{Author Disclosure Statement}

No competing financial interests exist.

\section{References}

1. Benjamin-Neelon SE. Position of the American Dietetic Association: Benchmarks for nutrition in child care. J Am Diet Assoc 2018; 118:1291-1300.

2. Institute of Medicine. Early Childhood Obesity Prevention Policies. The National Academies Press: Washington, DC, 2011.

3. Benjamin SE, Cradock A, Walker EM, et al. Obesity prevention in child care: A review of US state regulations. BMC Public Health 2008;8:188

4. Ogden CL, Carroll MD, Fryar CD, et al. Prevalence of obesity among adults and youth: United states, 2011-2014. NCHS Data Brief 2015;219:1-8.

5. Cunningham SA, Kramer MR, Narayan KMV. Incidence of childhood obesity in the United States. N Engl J Med 2014;370: 403-411.

6. Gordon-Larsen P, The NS, Adair LS. Longitudinal trends in obesity in the US from adolescence to the third decade of life. Obesity 2010;18:1801-1804

7. Singh AS, Mulder C, Twisk JWR, et al. Tracking of childhood overweight into adulthood: A systematic review of the literature. Obes Rev 2008;9:474-488.

8. Natale RA, Messiah SE, Asfour L, et al. Role modeling as an early childhood obesity prevention strategy: Effect of parents and teachers on preschool children's healthy lifestyle habits. $J$ Dev Behav Pediatr 2014;35:378-387.

9. Glickman D, Parker L, Sim LJ, et al. Accelerating Progress in Obesity Prevention: Solving the Weight of the Nation. The National Academies Press: Washington, DC, 2012. 
10. Benjamin Neelon SE, Mayhew M, O'Neill JR, et al. Comparative evaluation of a South Carolina policy to improve nutrition in child care. J Acad Nutr Diet 2016;116:949-956.

11. Lessard L, Lesesne C, Kakietek J, et al. Measurement of compliance with New York City's regulations on beverages, physical activity, and screen time in early child care centers. Prev Chronic Dis 2014;11:E183.

12. Natale RA, Lopez-Mitnik G, Uhlhorn SB, et al. Effect of a child care center-based obesity prevention program on body mass index and nutrition practices among preschool-aged children. Health Promot Pract 2014;15:695-705.

13. Benjamin Neelon S, Taveras E, Østbye T, et al. Preventing obesity in infants and toddlers in child care: Results from a pilot randomized controlled trial. Matern Child Health J 2014;18:12461257.

14. Lessard L, Williams Leng S, Brennan R. Consistency of compliance with nutrition-related regulations among Delaware child care centers. Child Obes 2013;9:233-239.

15. Larson N, Ward DS, Neelon SB, et al. What role can child-care settings play in obesity prevention? A review of the evidence and call for research efforts. J Am Diet Assoc 2011;111:1343-1362.

16. Laughlin L. Who's minding the kids? Child care arrangements: Spring 2011. Curr Popul Rep Ser.P-70 Househ Econ Stud no. 135. 2013.

17. Fox M, Glantz F, Endahl J, et al. Early Childhood and Child Care Study. United States Department of Agriculture: Alexandria, VA, 1997.

18. Frisvold D, Lumeng JC. Expanding exposure: Can increasing the daily duration of head start reduce childhood obesity? J Hum Resour 2009;46:373-402.

19. Lessard L, Breck A. Childhood obesity prevention in childcare settings: The potential of policy and environmental change interventions. Curr Obes Rep 2015;4:191-197.

20. Huang TT, Drewnosksi A, Kumanyika S, et al. A systems-oriented multilevel framework for addressing obesity in the 21 st century. Prev Chronic Dis 2009;6:A82.

21. Cohen DA. Obesity and the built environment: Changes in environmental cues cause energy imbalances. Int J Obes (Lond) 2008; 32:S142.

22. Khan LK, Sobush K, Keener D, et al. Recommended community strategies and measurements to prevent obesity in the United States. MMWR Recomm Rep 2009;58:1-26.

23. American Academy of Pediatrics. Caring for our Children: National Health and Safety Performance Standards; Guidelines for Early Care and Education Programs. American Academy of Pediatrics: Elk Grove Village, IL, 2011.

24. Slining MM, Benjamin Neelon SE, Duffey KJ. A review of state regulations to promote infant physical activity in child care. Int $J$ Behav Nutr Phys Act 2014;11:139.

25. US Government Accountability Office. Child Care: State Efforts to Enforce Safety and Health Requirements. GAO-04-786, 2004.

26. Independent Child Care Centers: A Child and Adult Care Food Program Handbook. United States Department of Agriculture: Washington, DC, 2014.

27. Ritchie LD, Boyle M, Chandran K, et al. Participation in the child and adult care food program is associated with more nutritious foods and beverages in child care. Child Obes 2012;8:224-229.

28. Korenman S, Abner KS, Kaestner R, et al. The child and adult care food program and the nutrition of preschoolers. Early Child Res $Q$ 2013;28:325-336.

29. Liu ST, Graffagino CL, Leser KA, et al. Obesity prevention practices and policies in child care settings enrolled and not en- rolled in the child and adult care food program. Matern Child Health J 2016;20:1933-1939.

30. Gabor V, Mantinan K, Rudolph K, et al. Challenges and opportunities related to implementation of child care nutrition and physical activity policies in Delaware. Altarum Institute: Washington, DC. 2010.

31. Nanney MS, LaRowe TL, Davey C, et al. Obesity prevention into early child care settings: A bistate (Minnesota and Wisconsin) assessment of best practices, implementation difficulty, and barriers. Health Educ Behav 2017;44:23-31.

32. Dev D, Carraway-Stage V, Schober DJ, et al. Implementing the academy of nutrition and dietetics benchmarks for nutrition education for children: Child-care providers' perspectives. J Acad Nutr Diet 2017;117:1963-1971.

33. Carroll JD, Demment MM, Stiles SB, et al. Overcoming barriers to vegetable consumption by preschool children: A child care center buying club. J Hunger Environ Nutr 2011;6:153-165.

34. Hughes CC, Gooze RA, Finkelstein DM, et al. Barriers to obesity prevention in head start. Health Aff 2010;29:454-462.

35. Monsivais $P$, Johnson DB. Improving nutrition in home child care: Are food costs a barrier? Public Health Nutr 2012;15:370-376.

36. Byrd-Williams C, Dooley EE, Sharma SV, et al. Best practices and barriers to obesity prevention in head start: Differences between director and teacher perceptions. Prev Chronic Dis 2017;14:E139.

37. South Carolina Childcare: ABC Grow Healthy Standards. www scchildcare.org (last accessed February 7, 2018).

38. Whitaker RC, Gooze RA, Hughes CC, et al. A national survey of obesity prevention practices in Head Start. Arch Pediatr Adolesc Med 2009;163:1144-1150.

39. Helfrich CD, Li Y-F, Sharp ND, et al. Organizational readiness to change assessment (ORCA): Development of an instrument based on the promoting action on research in health services (PARiHS) framework. Implement Sci 2009;4:38.

40. Kitson A, Harvey G, McCormack B. Enabling the implementation of evidence based practice: A conceptual framework. Qual Health Care 1998;7:149-158.

41. Kitson AL, Rycroft-Malone J, Harvey G, et al. Evaluating the successful implementation of evidence into practice using the PARiHS framework: Theoretical and practical challenges. Implement Sci 2008;3:1.

42. Harvey G, Kitson A. PARiHS revisited: From heuristic to integrated framework for the successful implementation of knowledge into practice. Implement Sci 2016;11:33.

43. Benjamin SE, Ammerman AS, Ward DS, et al. An intervention to promote healthy weight: Nutrition and physical activity selfassessment for child care (NAP SACC) theory and design. Prev Chronic Dis 2007;4:A67.

44. Benjamin SE, Neelon B, Ball SC, et al. Reliability and validity of a nutrition and physical activity environmental self-assessment for child care. Int J Behav Nutr Phys Act 2007;4:29.

45. Murphy SP, Yaktine AL, Suitor CW. Child and Adult Care Food Program: Aligning Dietary Guidance for All. The National Academies Press: Washington, DC, 2011.

46. Child and adult care food program (CACFP). United States Department of Agriculture. https://www.fns.usda.gov/cacfp/meals-and-snacks (last accessed January 8, 2018).

47. Russell CG, Worsley A, Liem DG. Parents' food choice motives and their associations with children's food preferences. Public Health Nutr 2015;18:1018-1027.

48. Ventura AK, Worobey J. Early influences on the development of food preferences. Curr Biol 2013;23:401.

49. Beauchamp GK, Mennella JA. Early flavor learning and its impact on later feeding behavior. J Pediatr Gastroenterol Nutr 2009;48: $25-30$ 
50. Beauchamp GK, Mennella JA. Flavor perception in human infants: Development and functional significance. Digestion 2011;83:1-6.

51. Wardle J, Herrera ML, Cooke L, et al. Modifying children's food preferences: The effects of exposure and reward on acceptance of an unfamiliar vegetable. Eur J Clin Nutr 2003;57:341-348.

52. Harris G, Coulthard H. Early eating behaviours and food acceptance revisited: Breastfeeding and introduction of complementary foods as predictive of food acceptance. Curr Obes Rep 2016;5: $113-120$.

53. Dazeley P, Houston-Price C. Exposure to foods' non-taste sensory properties. A nursery intervention to increase children's willingness to try fruit and vegetables. Appetite 2015;84:1-6.

54. Schindler JM, Corbett D, Forestell CA. Assessing the effect of food exposure on children's identification and acceptance of fruit and vegetables. Eat Behav 2013;14:53-56.

55. Savage JS, Fisher JO, Birch LL. Parental influence on eating behavior. J Law Med Ethics 2007;35:22-34.

56. Skinner JD, Carruth BR, Bounds W, et al. Children's food preferences. J Am Diet Assoc 2002;102:1638-1647.

57. van der Horst K, Ferrage A, Rytz A. Involving children in meal preparation: Effects on food intake. Appetite 2014;79:18-24.

58. Namenek Brouwer RJ, Benjamin Neelon SE. Watch me grow: A garden-based pilot intervention to increase vegetable and fruit intake in preschoolers. BMC Public Health 2013;13:363.

59. Daniel C. Economic constraints on taste formation and the true cost of healthy eating. Soc Sci Med 2016;148:34-41.

60. Morgan GG. The director as a key to quality. In: Culkin ML (ed), Managing Quality in Young Children's Programs. Teachers College Press: New York, NY, 2000.
61. Zandvoort Mv, Tucker P, Irwin JD, et al. Physical activity at daycare: Issues, challenges and perspectives. Early Years 2010;30: $175-188$

62. Lyn R, Evers S, Davis J, et al. Barriers and supports to implementing a nutrition and physical activity intervention in child care: Directors' perspectives. J Nutr Educ Behav 2014;46:171180.

63. Smith TM, Blaser C, Geno Rasmussen C, et al. Assessment of nutrition and physical activity practices using self-report and observation in early care and education across multiple US states. Public Health Nutr 2017;20:1692-1698.

64. Jones J, Yoong SL, Wyse R, et al. Improving the impact of obesity prevention interventions in the childcare setting: The need for a systematic application of implementation science. J Paediatr Child Health 2017;53:211-213.

65. Wolfenden L, Jones J, Williams CM, et al. Strategies to improve the implementation of healthy eating, physical activity and obesity prevention policies, practices or programmes within childcare services. Cochrane Database Syst Rev 2016;10:1-94.

Address correspondence to:

Daniel A. Zaltz, MPH

Department of Health, Behavior, and Society Johns Hopkins Bloomberg School of Public Health

$615 \mathrm{~N}$ Wolfe Street

Baltimore, MD 21205

E-mail:dzaltz1@jhu.edu 